\title{
A Multifaceted Editing and Reflection Project
}

\section{The DEE-CR Project}

\section{Drew M. Loewe}

St. Edward's University (drewml@stedwards.edu)

\section{Relevant Contexts for the Assignment}

Nationwide, the number of undergraduate writing majors has grown in the past twenty years, even in the face of enrollment challenges and shifting institutional priorities. As Louise Wetherbee Phelps explains, despite difficulties in tracking "reliable and stable data" on independent writing programs, self-reported case studies and other data establish that such programs have flourished even "during times of turbulence and disruptive change in higher education" (Phelps, 2019, p. vii). Writing majors aim to help students develop skills and experience in writing, argumentation, rhetoric, and editing so that they can communicate better and help others do the same. Specialized courses in editing, usually as part of upper-division coursework, are a staple of writing majors, such as those documented in Giberson et al. (2015) and Matzen and Abraham (2019).

St. Edward's University, where I have taught this assignment, is a small, primarily undergraduate university in Austin, Texas and a designated Hispanic-Serving Institution. Since 1987, St. Edward's has offered an undergraduate degree in writing and rhetoric. The Writing and Rhetoric (WRIT) major offers students four concentrations: creative writing, professional writing, journalism and digital media, or a flexible "general" concentration. WRIT 3330: The Craft of Editing is a junior-level course in the major's core and thus is taken by all WRIT students. The course builds on an earlier course in grammar and style (or journalistic copyediting for those concentrators).

WRIT 3330 features two categories of work: a) daily work and b) two major assignments. A typical daily work session features pre-class preparation and a hands-on activity during class time. To prepare for class sessions, students complete assigned readings from two required textbooks-Williams and Bizup's (2017) Style: Lessons in Clarity and Grace and The Chicago Manual of Style (2017)-and other materials on topics such as levels of edits, the editor's role, clarity, sentence emphasis, cohesion and coherence, structure, concision, or usage. After completing the readings, students answer discussion prompts on the course learning management system (LMS). The discussion prompts help students to understand concepts from the readings and

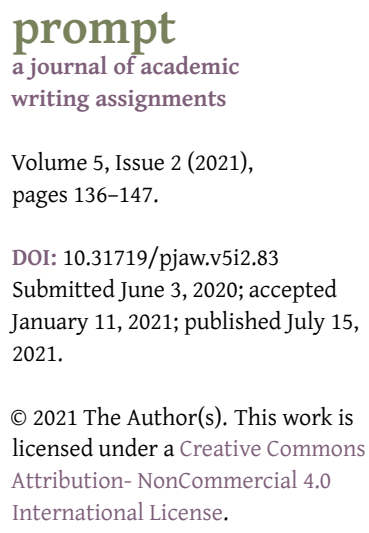

(C) 2021 The Author(s). This work is licensed under a Creative Commons Attribution- NonCommercial 4.0 International License. 
connect them to their own experiences as writers and editors. The discussion posts also help to identify areas of confusion that can be addressed at the beginning of the class session. During the class session, students are given a text to work on in small groups so that they can apply course concepts and gain experience in editing for particular concerns. After the groups have hashed out their editorial suggestions for the day's text, the class comes together as a whole to compare the groups' suggestions and connect the day's work to previous lessons. Work from these hands-on sessions is shared in a Google Drive folder that makes the day-to-day work of the course visible and accessible.

In addition to daily work, the course asks students to complete two major multi-week assignments: the individual DEE-CR assignment and a collaborative developmental editing assignment. These two assignments involve significant time for invention and review and can be revised and resubmitted after grading. Revision policies encourage students to meet with the instructor, apply the feedback they receive, and rework submissions for a (potentially) replaced grade. Those policies also ask students to write a detailed revision memo and use Microsoft Word or other software to make a "blackline" document showing all differences between the original and revised submissions. ${ }^{1}$

\section{DEE-CR Project Goals and Features}

The DEE-CR assignment is the first of the two major projects in the course. It aims to help students to develop several skills and dispositions:

a) Student interest and accountability in choosing texts to work with (albeit with some constraints);

b) Sufficient research to establish the context, genre, audience, and purpose of the text to be edited;

c) Accurate description of the chosen text and its context;

d) Evaluation of the text's effectiveness and identification of areas for improvement via the intervention of a supportive editor;

e) Judicious editing via professional software;

f) Clear, actionable, supportive feedback to the author; and

g) Metacognitive, synthetic reflection on experience.

The assignment is designed to help students to bridge the gap between working primarily with their own texts and working with others' texts effectively, precisely, and ethically. It asks students to describe, analyze, evaluate, and judiciously edit a text; use authoritative sources; develop clear, supportive communication; and reflect on their knowledge and experiences.

In years past, editing courses might have focused on hand markup of hard-copy texts, but digital technologies have changed how texts are produced and circulated (Arnett, 2013). Brumberger and Lauer (2015) studied 914 professional writing and editing advertisements and found that specific technologies mentioned in the ads included Microsoft Office; Adobe Acrobat; and image-editing, content management, and web authoring tools. In a later observational and interview-based study, Lauer and Brumberger (2019) found that careers in professional writing require employees to produce and edit a range of genres, no longer limited to the primarily textual. Yet even while primarily textual genres are no longer dominant in some contexts, employers continue to seek applicants skilled in written communication, problem-solving, and attention to detail (National Association of Colleges and Employers, 2020). Also, the WRIT major's internal data on alumni career outcomes show that our graduates identify skills in editing, grammar, and revision of texts as crucial to their success. Thus, the DEE-CR assignment 
asks students to use professional software to edit digitally and to choose a primarily textual genre.

\section{D: Describe}

The choice of text is a crucial moment for students and forms the basis of the assignment's first section ("D" for Describe). Because of local contexts, the assignment requires a non-fiction text. At St. Edward's, all WRIT majors, regardless of their concentration, take one introductory course in all of the concentrations. Thus, students in WRIT 3330 have already taken at least one creative writing course that teaches them how to give editorial advice to fiction writers for plot, characterization, setting, and dialogue. Moreover, about half of WRIT majors specialize in creative writing. As a result, all WRIT students have received practice in editing fiction, and about half of them will receive extensive practice. To help students continue to develop a broad range of editing skills, this assignment stipulates a non-fiction text.

A few other restrictions are in place: students may not work on their own writing or on fellow students' writing (such as papers written for other classes), nor are they allowed to select texts from collections of bad writing. Finally, they may not choose articles in the university newspaper because such texts are fairly short and students may work for the paper as paid editors. These guidelines help students to examine a greater range of texts than they might otherwise choose and don't duplicate other editing experiences that students receive throughout the WRIT major.

At first, some students will choose short, insubstantial texts or texts that are too extensive. This challenge is not fixable under any simple rule. Because is more valuable for students to work on texts that they choose than for me to assign a particular text, making the process of text selection a guided negotiation with adequate time and support is critical. Discussion board posts, workshops, and individual conversations with students are crucial to working out the selection of texts. It is also important to be flexible; for instance, representative samples of a lengthy work might be valuable if the student can show a particular reason for wanting to work with a text too extensive as-is. By the same token, a shorter text is not necessarily insubstantial.

The texts that students have chosen so far vary significantly; they include university communications; press releases; opinion articles; corporate documents; various club, governmental, and organization websites; communications they receive from landlords; and others. To help future classes explore their own choices, I have made a list of the texts students have chosen. The list, which can be supplemented every time the assignment is taught, can help in exploratory activities and in negotiating students' choices. To help students choose a text, I ask them to post a range of possible texts that they are considering to an LMS discussion board and answer a written prompt about each possible text. The prompt asks students to describe the text, identify where they found it, explain what they already know about it, and explore why they find it possibly fruitful to work on. In class workshops, the choice of text can then be hashed out.

One recurring mantra of the course is that "no text comes out of a vacuum or enters one." Thus, students must provide a reasonably full picture of the context and exigence for their chosen text via research. WRIT students at the junior level will have already gained experience in contextualizing texts through earlier required courses, including courses in rhetorical analysis and workplace writing. Class workshops and pre-class posts to the course's discussion board guide students to develop the background necessary to make warranted observations about the text's audience, purpose, and genre expectations. This background material could include contemporaneous news accounts, additional materials from or about the organization or author that produced the text, or authoritative guidance on genre expectations. Students are expected to integrate and cite all sources that help them establish the situational exigence from which the text arose.

prompt 5.2 (2021) | Loewe, A Multifacted Editing and Reflection Project 


\section{E: Evaluate}

The second section of the assignment ("E" for Evaluate) asks students to evaluate the text in its context, to judge how effective it is, and to point out opportunities to help the author better achieve their goals. Students build upon earlier work in the WRIT curriculum, including the prerequisite course in grammar and style and a 2000-level course in analyzing rhetoric, and use new material from this course to ground their evaluation of the text in defensible judgments. The two required textbooks help students to anchor particular judgments in well-supported rationales. If their chosen text was subject to an institutional style guide or publication's house style, the assignment asks the student to identify and use those particular rules in editing the text and to include them in their submission, typically by a hyperlink.

\section{E: Edit}

The third section of the assignment ("E" for Edit) is the actual editing. Drawing on the daily work components of the course, students work closely with the text, deciding what to keep and what to change, what to rework, what to move, what to combine, condense, and the like so their edits advance the author's goals and do not merely reflect the student's own preferences. To show their edits clearly, most students use Microsoft Word's "track changes" feature or the editing tools in Adobe Acrobat, both widely adopted in professional editing contexts. At St. Edward's, students have access to the Office 365 suite as part of the university's IT support. Students may also subscribe to the Adobe Creative Cloud at a discount, and many WRIT students do. Also, all public computers on campus have Office and Creative Cloud installed.

But even with these supports in place, I learned to be flexible in specifying particular software. Alternative change-tracking word processors, such as the free, open-source Libreoffice Writer can also work well, and Google Docs has recently added a document comparison feature. Also, free PDF applications such as Adobe Reader, Mac Preview, or Xodo provide commenting tools that can be used to edit texts effectively. At St. Edward's, all students have access to Google Workspace and might prefer to work in Google Docs before exporting to other formats. With support, students can find a solution that works for them, but some class time for exploration and troubleshooting is necessary. While most students have used word processors and PDF reading applications before, they do not have much practice in using digital software in an editing workflow beyond the commenting feature of Google Docs. Thus, direct instruction and practice are necessary so that each student can make an effective choice of digital tool and feel confident in using it.

\section{C: Communicate}

The fourth section of the assignment ("C" for Communicate) asks students to write an (unsent) email addressed to the author so they can communicate clearly and diplomatically, explain their edits, ask questions, and ground editorial feedback in sound foundations. In this section, students identify and describe their edits, ask questions of the author where needed, and make a specific request for action by the author to review and communicate about the edits. The Chicago Manual of Style (2017) and sources such as Mackiewicz and Riley (2003) on clarity and politeness strategies, and Speck (1991) on editorial dialogue help students to develop their emails and test different strategies to communicate with authors. The simulated author-editor relationship assumes a future exchange where the edits are discussed and finalized. The email to the author is simulated, not sent. While Spinuzzi (1996) rightly warns of the dangers of "pseudotransactionality"-writing only for the teacher even in professional writing genresstudents do not email the author because the pressure to communicate directly with the author might skew students' choices of texts and editorial advice. Many authors are unlikely to welcome 
an unsolicited email from an undergraduate with editorial advice. Moreover, I teach the project in the context of a 4/4 workload of writing classes, so the added labor and supervision that direct communication with the author would entail are not sustainable. Asking students to work within an imagined author/editor relationship has, so far, been successful (see student comments below). To enable that imagined relationship, the advice that I give to students in responding to this section of the project underscores how important it is to establish the text's context and ground judicious edits in sound rationales. In my comments to students, I do not pretend to be the author of the text being edited, but rather act as a guide to helping the student make their suggestions clear, warranted, nuanced, sensitive, and helpful if, in the imagined situation, the communication were to be sent to the author.

\section{R: Reflect}

The assignment's final section is (" $R$ " for Reflect) asks students to reflect on their choices in editing the text and communicating with the author. As Yancey (2016) explains, reflection is "an epistemological practice based in experience and the theorizing of that experience" (p. 318). Thus, the goal of this section is for students to build a substantive "so what?" point about the problems and opportunities of editing texts, and to connect their work on the DEE-CR assignment to their previous experiences and their emerging skills as editors. This section helps students to trace the journey from understanding a text in its context to making judicious edits to communicating them to the author to making knowledge about how editing someone else's text could help them in their own writing and editing. This final section imagines a composite audience: the student speaking on the page to their past and present selves (i.e. a first-person explanation of "what I learned from this experience" and "what I might do with that knowledge") and to me as the evaluator of their work looking for evidence of their efforts to make something of their experience. One advantage to teaching in a writing major is that students are accustomed to submitting writer's memos, revision memos, reflective essays, and other metacognitive texts that ask them to make knowledge from experience. Despite what might seem to be yet another "reflect on this" requirement, students take this section of the assignment quite seriously. They want to make connections between academic and personal experiences and want assignments to be meaningful. So long as this section contains evidence of a good-faith effort to make meaning from experience, I comment more as a conversation partner than an evaluator in this section.

\section{Reflection and Teaching Notes}

Overall, comments in course evaluations show that students see the DEE-CR assignment as valuable, realistic, and relevant. As one student put it, the assignment requires both "small-scale sentence-level editing" and "meta-analysis" of larger concepts such as coherence and cohesion. Another student commented that "My edits are much more judicious compared to how they were before" given the need to ground them in relevant authorities and communicate them gracefully.

Students' comments in the Reflection section provide some evidence of how they are building knowledge from their experiences. ${ }^{2}$ For example, one student wrote that "I didn't anticipate how frustrating it would be to . . restrain myself from just rewriting things into my own conception of 'better.' . . . If there was a change I couldn't justify in the text, then it made me stop and really ask why I wanted a change there at all." That same student added that "Having to address this project as though the author was going to read it . . changed the tone of my editing. . . . That [experience] is something I should bring forward into all the editing I do." 
Table 1. Suggested Timeline for DEE-CR Project. Assignment Week 1 corresponds to Week 4 in the course, after basics of editing have been practiced.

\section{Week(s) Activity}

1 Introduction to assignment, preliminary activities.

2 Possible texts explored.

3-4 Negotiation of/commitment to chosen text, in-process workshops, discussions, and activities; iteration/feedback on low-stakes drafts.

5 Peer review of full drafts, polishing/editing workshop, submission for grading/feedback/revision cycle begins.

7 or 8 Revisions submitted.

Another student drew on their experiences working in the campus writing center, noting that "I identified places where I needed to use directive language for the [text] to make sense. In doing this, I was reminded of my experience as a peer student mentor in the Writing Center." Finally, one student noted that working with a text and trying not to "do more harm than good" helped them "see similar patterns in my own writing."

In addition to the challenges of finding a suitable text discussed above, another challenge is finding the optimal amount of time to complete the assignment. As Bisaillon (2007) notes, editors often work under tight deadlines; thus, an adept editor must be able to size up a text quickly and provide useful advice. The assignment cannot take too long, or it loses some of its value. However, significant time (several weeks) is necessary because each portion of the assignment, not just the editing, challenges students to develop their rhetorical, analytical, synthetic, and reflective capabilities. Readers may consider shortening or lengthening the suggested timeline (see Table 1) for their own contexts.

Finally, the assignment may be adapted in a couple of ways. First, it could be made collaborative by assigning students to work in small teams and by building in additional elements for reflection on the collaborative nature of editing. Making the project collaborative could mitigate the additional work and supervision necessary if students were to communicate directly with authors. One way to add these elements of collaboration and communication with authors would be to adapt the project for service learning. If so adapted, an editorial agreement that specifies the nature and scope of work and manages expectations will be crucial. It may also be necessary to extend the timeline to account for client schedules and instructor feedback before students communicate with the client.

In teaching this assignment, I have been excited by students' choices of texts, which underscore the importance of editing in a wide range of writing situations and genres. Writing mediates much of human activity; thus, opportunities for improving writing are everywhere. I have also been impressed by students' efforts to really understand the situation, purpose, and constraints that the writer was facing so that their editorial advice was judicious and supportive. Assignments that blend the conceptual with the practical and that ask students to make knowledge from their experiences play a small part in designing a better future mediated by writing. 


\section{ASSIGNMENT}

\section{DEE-CR Project}

\section{(Describe, Evaluate, Edit, Communicate, Reflect)}

\section{Purposes}

- Evaluate and edit a text judiciously for audience, purpose, genre, forum, style, diction, tone, and mechanics.

- Communicate effectively and supportively to an author.

- Make knowledge from your experience.

\section{Overview}

- This assignment asks you to select a particular non-fiction text "out there in the world" that you believe would benefit from the attention of an informed, adept editor who can help the writer better achieve their goals.

- You will first describe the text and contextualize it, then evaluate it in terms of audience, purpose, genre, forum, style, diction, tone, and mechanics.

- Then, you will edit the text to better achieve the writer's purposes. Refer to our textbooks (the Chicago Manual of Style and Williams and Bizup's Style: Lessons in Clarity and Grace) and other assigned resources to ground your efforts in specific concepts and strategies.

- Finally, you will reflect on the edits that you made to the text, offer rationales for why you made them and how they improve the text, and offer a "so what?" knowledge-making point from your having edited the text.

\section{Section Requirements}

Submit one consecutively paginated PDF with these seven parts, in this order:

- D: Part 1, the Description, should inform readers where you found the text, identify its author(s) and audience(s), purpose(s), genre, and forum. The purpose of this section is to contextualize the text so your edits are not just abstractions or preferences. You will have to do some research to establish these grounding conditions. Cite your sources using MLA 8th format, both in this section (in-text citations) and in a Works Cited. You'll need roughly 500 words to develop this section completely yet concisely.

- E: Part 2, the Evaluation, should evaluate the text in terms of how effective or ineffective it is, given the context you explained in the previous section. Be specific in your evaluative comments about audience, purpose, genre, forum, style, diction, tone, and mechanics. What needs editing and why? What needs to be left as it stands and why? What levels of edits are needed and why? What does the text do well, poorly, or not at all? Which concepts from assigned materials (be specific) will you use in editing the text to better achieve its purposes? You'll need roughly 500 words to develop this section completely yet concisely.

- E: Part 3, the Editing part, asks you to edit the text and to show those edits clearly. Use Microsoft Word, Libreoffice Writer, or the markup tools in Adobe Acrobat, Mac Preview, or Xodo. I will help you select a tool that works for you. The purpose of this section is to clearly show all modifications to the text. If you have to attach the edited text as an appendix and just refer to it here, that's fine, too. Talk to 
me about what's best to do, given the length and complexity of your text. This section is simply the edited text, showing all modifications; you'll reflect on the edits in the next section.

- C: Part 4, the Communicate part, asks you to communicate about your editorial emendations to the author in the form of an email. The email will require you to refer to spelling or style questions still to be resolved (those that could go more than one way), a list of issues, an overview of changes to the text, and a request for action. Your communication needs to be clear, supported, tactful, actionable, and useful. Use the strategies identified by Mackiewicz and Riley in their article on the "editor as diplomat."

- R: Part 5, the Reflection, asks you to reflect on how the text is improved by your edits. Recall that editing works at both the macro and micro levels and is intended to best help the text accomplish its purposes. Offer a "so what?" point about the problems, opportunities, and challenges of editing texts that your work on this particular text helps to illuminate. What surprised you? What did you learn from the process of editing this text? What did you draw on from your previous experiences (in or out of school contexts) about giving and receiving feedback? What did you learn that could carry over to other writing and editing situations?

- Part 6 is a simple Works Cited in MLA format. Here you will cite the original text and all sources used in establishing the text's context in the Description section.

- Part 7 is an Appendix consisting of the original unedited text-- retyped, embedded as a screenshot, scanned, or otherwise presented as it was when you found it. I can help you with scanning text, with optical character recognition (OCR), and other workarounds to save any drudgery here.

- After Part 7, put a page break. On the last page, identify the one item that you most want me to comment on when I evaluate your work. Use a short paragraph to do so.

\section{Rules and Advice}

- You have to choose a text "in the wild" (not from a textbook, an exercise, a collection of bad writing, etc.).

- Choose a text that you are interested in--but remember that "interest" can take many forms. Don't just settle for the first thing you see. We will have in-class activities designed to help you choose a text and to help your classmates with their own choices.

- Nonfiction prose texts only.

- No "academic paper" texts, such as a class paper.

- No student newspaper texts.

- Choose a text with "enough" to work with. While that standard is loose, if you choose a text that just needs a couple of commas added or removed (or is very short), you won't have much to work with or reflect upon. This assignment assumes that you will see a genuine need for substantive macro/micro editing of the text. By the same token, if you choose a very long text, you might not have enough time. We will negotiate your selection of a text to work with.

- Make sure that your edits are judicious and that they achieve the text's purposes better than the text did before you edited it. Don't chop out essential information (maybe it can be condensed) or just appropriate the text. Don't introduce new errors. 
- If your chosen text is subject to a particular style guide, work with that style guide, submit it (e.g., with a link), and be sure to describe how you used that guide to make choices.

- If your chosen text is not subject to a particular style guide or that guide does not provide a clear answer to a particular question, use CMOS as your style guide. In particular, use CMOS for:

- Section 5.250, the Glossary of Problematic Words and Phrases

- Sections 5.251-.260 on biased language

- Section 6 on Punctuation

- Section 7 on Spelling, Distinctive Treatment of Words, and Compounds

- Section 8 on Names, Terms, and Titles of Works

- Section 9 on Numbers

- Section 10 on Abbreviations

- Section 11 on Languages Other than English

- Be prepared to articulate a rationale for all modifications to the text.

- Ask questions early and often. Participate in low-stakes drafting and invention activities.

\section{Evaluation Criteria}

\section{Description section}

Expectations

$\square$ Informs readers where you found the text, identifies its author(s), audience(s), purpose(s), genre, and forum.

$\square$ Contextualizes the text so your edits are not just abstractions.

$\square$ If sources are needed to establish this context, they are incorporated effectively and cited in the text and a Works Cited.

Comments, Questions, and Advice:

\section{Evaluation Section}

Expectations

$\square$ Evaluates the text in terms of how effective or ineffective it is, given the context laid out in the previous section. Explains what the text does well, poorly, or not at all.

$\square$ Clear on what needs editing and why.

$\square$ Refers accurately to specific concepts from CMOS, SLCG, or other relevant materials particular to this text and its context.

Comments, Questions, and Advice:

\section{Editing Section}

Expectations

$\square$ Shows the chosen text and your edits clearly by using change-tracked word processing or clear PDF markup.

$\square$ Edits improve the text for its purposes and context, are judicious, and do not introduce new errors. 


\section{Communication section}

Expectations

$\square$ Uses style sheet, issues section, and overview of changes to the text to separate levels of comments and to balance depth and breadth.

$\square$ Clear, supported, tactful, actionable, useful to the author.

Comments, Questions, and Advice:

\section{Reflection section}

Expectations

$\square$ Reflects on the edits you made, where you suggested modifications to the text (and where you did not), and how the text is improved by your edits, micro and macro.

口 Offers "so what?" points about the problems, opportunities, and challenges of editing texts that your work on this text helps to illuminate. (Possible questions to develop: What surprised you? How were you judicious in your edits? What did you draw on from your previous experiences [in or out of school]? What did you learn that could carry over to other situations?)

Comments, Questions, and Advice:

\section{Form and Mechanics}

All sections present, in order (Description, Evaluation, Editing, Communication, Reflection, Works Cited, Appendix), in consecutively paginated PDF?
$\square$ Yes
$\square$ No

Unhampered by disruptive errors (e.g. ineffective sentence fragment, comma splices, fused sentences) or accumulations of minor errors (e.g., dropped quotes, typos, it's/its, missing/ repeated words)?

$\square$ Yes

$\square$ No

Comments, Questions, and Advice:

\section{Content (90\% of grade)}

$\square$ Meets All Expectations-100\%

$\square$ Meets Most Expectations-85\%

$\square$ Shows Effort, but Doesn't Yet Meet Most Expectations-70\%

$\square$ Not Assessable-0\% 
Form and Mechanics (10\% of grade)

$\square$ Meets All Expectations-100\%

$\square$ Meets Most Expectations-85\%

$\square$ Shows Effort, but Doesn't Yet Meet Most Expectations-70\%

$\square$ Not Assessable-0\%

\section{Overall Grade for Submission (Content + Form and Mechanics) \\ $\square$ Meets All Expectations-100\% \\ $\square$ Meets Most Expectations-85\% \\ $\square$ Shows Effort, but Doesn't Yet Meet Most Expectations-70\% \\ $\square$ Not Assessable-0\%}

Overall Comments and Priorities for Revision:

\section{Notes}

${ }^{1}$ Revision policies and procedures can be found at drewloewe.net/policies.

${ }^{2}$ Quoted comments here are used with students' written permission.

\section{Supplementary Material}

For supplementary material accompanying this paper, including a PDF facsimile of the assignment description formatted as the author(s) presented it to students, please visit https: //doi.org/10.31719/pjaw.v5i2.83.

\section{References}

Arnett, E. J. (2013). Teaching a college-level editing class. Proceedings of the Society for Technical Communication Summit '13, 229-233. https: / / summit. stc.org / wp-content/ uploads / 2013 / 04 / STC- 2013Technical-Communication-Summit-Proceedings.pdf\#page $=235$

Bisaillon, J. (2007). Professional editing strategies used by six editors [doi: 10.1177/0741088307305977]. Written Communication, 24(4), 295-322. https://doi.org/10.1177/0741088307305977

Brumberger, E., \& Lauer, C. (2015). The evolution of technical communication: An analysis of industry job postings. Technical Communication, 62(4), 224-243. https://www.ingentaconnect.com/content/ stc/tc/2015/00000062/00000004/art00002

The Chicago manual of style (17th ed.). (2017). University of Chicago Press. Retrieved November 4, 2020, from https://press.uchicago.edu/ucp/books/book/chicago/c/bo25956703.html

Giberson, G., Nugent, J., \& Ostergaard, L. A. (Eds.). (2015). Writing majors: Eighteen program profiles. Utah State University Press.

Lauer, C., \& Brumberger, E. (2019). Redefining writing for the responsive workplace. College Composition and Communication, 70(4), 634-663.

Mackiewicz, J., \& Riley, K. (2003). The technical editor as diplomat: Linguistic strategies for balancing clarity and politeness. Technical Communication, 50(1), 83-94. https://www.ingentaconnect.com/ content/stc/tc/2003/00000050/00000001/art00009

Matzen, R. N., Jr., \& Abraham, M. (2019). Introduction: Looking toward an (inter)disciplinary future? In R. N. Matzen Jr. \& M. Abraham (Eds.), Weathering the storm: Independent writing programs in the age of fiscal austerity (pp. 3-18). Utah State University Press.

National Association of Colleges and Employers. (2020). Key attributes employers want to see on students' resumes. Retrieved November 4, 2020, from https://www.naceweb.org/talent-acquisition/ candidate-selection/key-attributes-employers-want-to-see-on-students-resumes/

prompt 5.2 (2021) | Loewe, A Multifacted Editing and Reflection Project 
Phelps, L. W. (2019). Foreword: An invitation to read for resilience. In R. N. Matzen Jr. \& M. Abraham (Eds.), Weathering the storm: Independent writing programs in the age of fiscal austerity (pp. vii-xiii). Utah State University Press.

Speck, B. W. (1991). Editorial authority in the author-editor relationship. Technical Communication, 38(3), 300-315. Retrieved November 4, 2020, from http://www.jstor.org/stable/43095742

Spinuzzi, C. (1996). Pseudotransactionality, activity theory, and professional writing instruction [doi: 10.1207/s15427625tcq0503_3]. Technical Communication Quarterly, 5(3), 295-308. https://doi.org/ $10.1207 /$ s15427625tcq0503_3

Williams, J., \& Bizup, J. (2017). Style: Lessons in clarity and grace (12th ed.). Pearson.

Yancey, K. (2016). Defining reflection: The rhetorical nature and qualities of reflection. A rhetoric of reflection (pp. 303-320). Utah State University Press. 